\title{
Travel to a conference (obtaining funding)
}

\author{
K C B Tan, D J Betteridge
}

That first major scientific meeting tends never to be forgotten. Because until then senior, national, and internationally known colleagues are but names on well thumbed papers and reviews. Suddenly there they all are, in the flesh so to speak, either presenting new data or taking part in the discussion of the work of others. Somehow senior figures (at least most of them) seem to be approachable on these occasions and are readily available to give advice and help with scientific matters.

Of course, the occasion can be daunting and sometimes overwhelming if young research fellows are to present their first paper in front of the leading figures in their subject. Anxious thoughts cross the mind. Have I rehearsed enough? Will I dry up? How does the microphone work? Will I get my slides the wrong way up? Will professor so and so ask difficult questions? etc, etc. It is much better to have sampled the atmosphere of these large meetings - in some specialties there may be over 5000 delegates-before the fateful day of the first paper.

Later in your career the excitement of these meetings pales slightly through familiarity, but they remain a source of intellectual refreshment and ideas. New friendships are made, old ones are renewed, and mutual problems can be discussed. The benefits of attending national, European, and world congresses in your subject are incalculable, and this is especially true for younger people. But raising the money to get to them may seem to be an impossibility. Money can be particularly tight in the research years because available funds cover payment of only the basic salary with no units of medical time. Some of the larger units will have what are commonly called "slush" funds which can be used for funding travel to meetings; such units are relatively few.

So how do you set about raising the necessary money to cover travel and accommodation expenses? Furthermore, the registration fees for meetings seem to be rising exponentially and may well be over $£ 100$ a person for a large international meeting.

\section{Funding from specialist associations}

Most specialist associations set aside money, often from major pharmaceutical companies, for the provision of travel grants to junior members. Age limits vary but are usually below 35 years. It is therefore very important to join the appropriate specialist organisation at an early stage. Their funds are, of course, limited, and preference is often given to first and second authors of abstracts which have been accepted for presentation at the meeting. Detailed scrutiny of the advance notices for meetings is required as applications for assistance towards travel costs often have to be submitted at the same time as the research abstracts. This can be up to nine months before the meeting. If several abstracts are submitted from a single department some thought as to the order of joint authors can ensure maximum benefit for junior colleagues.

Hospital, London

WC1E 6AU

K C B Tan, MRCP, medical registrar

D J Betteridge, FRCP, reader in medicine

BrMed F 1989;299:1450-1

\section{Funding from employers}

Travel expenses, subsistence allowances, and registration fees can, in certain circumstances, be obtained from your employer, be it a university, or district, or regional health authority, depending on the particular grade of appointment. The overriding principle in negotiating this often tortuous bureaucracy is to plan well in advance. In most cases retrospective claims are not considered. It is not possible to detail here all the regulations concerning study leave and expenses, but enlist the support of your consultant or head of department where appropriate. The postgraduate dean and clinical tutor should point you in the right direction. It is unlikely that junior doctors will receive financial support from health authorities for overseas meetings except in the case of senior registrars presenting their own work. The same restrictions do not apply to university posts, and most universities have funds available for non-tenured staff, although these are strictly limited and often will not cover the cost of an overseas meeting.

\section{Other sources of funding}

\section{MAJOR GRANT AWARDING INSTITUTIONS}

It is worth applying to the major grant giving bodies such as the Medical Research Council and the Wellcome Foundation for travel grants, especially if you are already funded by them. Bear in mind, however, that the travel grants awarded by these institutions go mainly to support short visits to other research groups for the exchange of ideas or to learn new techniques. Of course, this important activity could appropriately follow a scientific meeting overseas. You must apply well in advance for these awards.

\section{ROYAL COLLEGES}

The royal colleges make travel grants available to members and fellows often in the form of named fellowships. These fellowships provide funds for postgraduate activities and research in prestigious overseas departments for varying lengths of time. They are not primarily designed for attendance at scientific meetings, but a scientific meeting could be an important part of the package of activities.

The Royal Society will consider applications for travel grants from postdoctoral fellows and senior doctors in certain circumstances, so it is worth while obtaining a copy of their regulations.

\section{PHARMACEUTICAL INDUSTRY}

The industry provides considerable funds for travel to and registration at major national and international meetings. This is often done in association with the local organisers of the particular specialist body, and the activity is acknowledged in the conference programme. Some pharmaceutical companies also advertise travel grants in the weekly journals, inviting applications, which are decided on a competitive basis. In both these instances preference is given to those presenting abstracts which have been accepted for presentation at the meeting.

It is a great advantage for a research fellow to have attended one of the major meetings before presenting his or her own work. But it is much more difficult to obtain funding in this instance unless the particular department where the fellow works has funds available. 
The pharmaceutical industry may be very useful here. Of course, it helps if the research fellow works in a specialty in which there is a lot of industry interest. In our view this is a legitimate activity, although some will disagree. Make initial approaches through the relevant local representatives as chances of obtaining funding are often enhanced if the representative is pushing the case. Turn down the offer to discuss this or that product over lunch but tactfully suggest that help towards the travel costs of the next European meeting would be a more worthwhile way to spend the budget.

\section{Make the most of the money raised}

Advance programmes for many international scientific meetings provide the facility for booking convenient hotel accommodation beforehand. Furthermore, members of particular specialty associations receive, unsolicited, details of "package" deals to attend forthcoming major meetings. We have never availed ourselves of these opportunities, believing that good, cheaper alternatives are often possible. This does not apply to national meetings when adequate and cheaper accommodation is to be had in university halls of residence. The traditional "bucket shops" which deal in the "unsold stocks" of airline tickets have been heavily criticised because of financial losses and nonarrival of tickets. But some of these outlets are good and efficient: the difficulty lies in knowing which fall into this category. If you want to deliver your talk to your colleagues at the meeting rather than to other stranded passengers at the airport it is best to use travel agents bonded to the Association of British Travel Agents (ABTA) or the International Air Transport Association (IATA) whenever possible.

Planning ahead is the most important consideration in obtaining the best deals. Cheaper excursion flights (stay includes a compulsory Saturday night) have to be booked at least two weeks ahead for most European flights and three weeks for those further afield. Consider charter flights and accommodation packages, such as City Breaks, which can be very good value, especially if you share a room with a colleague. Choosing an unpopular flight time (early morning, late night) may enable cheaper tickets to be obtained. For Europe it is worth considering rail travel, and for a small group travelling together driving may prove much cheaper. We know of some colleagues who actually camped out near one European city and travelled in daily for the meeting. For those not so hardy there are now plenty of available guides which detail cheap and clean basic accommodation in most cities.

\section{Conclusions}

It is well worth the challenge to raise money to attend the major meetings in your relevant specialty. An exchief known to us refused to give any financial help to his research fellows for travel. His parsimony led to an excellent training in raising money.

\title{
Lesson of the Week
}

\section{Osteogenesis imperfecta in the differential diagnosis of child abuse}

\author{
Colin R Paterson, Susan J McAllion
}

\section{Osteogenesis imperfecta may lead to a mistaken diagnosis of child abuse}

In children with unexplained fractures the differential diagnosis rightly includes non-accidental injury, but it also includes several bone disorders. One of the most important of these is osteogenesis imperfecta. This condition is not uncommon, but there may be little or no abnormality in the radiological appearances of the bone at the time of the first fracture. ${ }^{1-4}$ The frequency with which diagnostic difficulties may arise is not known. On the basis of the known prevalence of oteogenesis imperfecta it has been suggested that errors of diagnosis should rarely occur. ${ }^{+}$

This study was based on a continuing large survey of patients with osteogenesis imperfecta in the British Isles, some of the results of which have been reported..$^{5.7}$ The study includes 802 cases from the United Kingdom in which the diagnosis was not in doubt. This paper reports the extent to which these children were initially thought to have sustained nonaccidental injury.

\section{Subjects and methods}

Our register includes clinical details of cases referred after the diagnosis of osteogenesis imperfecta had been made by local paediatricians or orthopaedic surgeons or as a result of a family study. A detailed questionnaire was completed for each patient, and in about two thirds of cases the patient was also examined by one of us. In classifying the patients we used the scheme of Sillence and colleagues (table I) ${ }^{89}$ and had no difficulty in allocating to a Sillence type all but 53 patients. In as many cases as possible the original radiographs were reviewed.

We divided our patients into three groups in relation to the extent to which suggestions were made that the fractures were caused by child abuse. In 691 cases there was no problem in this respect, the diagnosis being made with confidence either at birth or at the time of the first fractures. In 96 cases the parents were accused of non-accidental injury on at least one occasion, but the period over which the difficulties continued was less than one week. In a group of 15 children parents had to contend with formal case conferences, care proceedings, and repeated interviews from social workers and police; in one case parents were prosecuted but acquitted.

\section{Results}

Table II summarises our findings in relation to the clinical types of the disorder. Not surprisingly, children with the type IVA and type IVB variants figured prominently in the group with diagnostic difficulties. In most of the type IVB cases the difficulty arose before teeth erupted. There were, however, surprisingly large numbers of patients with type I disease, in whom the diagnosis should have been apparent at the time of presentation by virtue of the scleral abnormality. In most cases in which we reviewed the radiographs the skeletal appearances were normal at this stage and radiology was unhelpful. This group of patients included many whose osteogenesis imperfecta arose as a
Correspondence to: $\mathrm{Dr}$ Paterson. 